\title{
Cholesteryl ester storage disease: endoscopic findings of an orphan disease
}

A 23-year-old man with normal antenatal history was admitted to hospital because of right hypochondrial pain, periodic nausea, and fatigue. The patient reported an episode of idiopathic jaundice with moderate fever 5 years previously. He was a non-smoker who did not drink alcohol nor take oral or intravenous drugs. Evaluation for viral hepatitis was negative. His physical examination revealed a high body mass index (BMI) of $32.2 \mathrm{~kg} /$ $\mathrm{m}^{2}$, his liver was palpable $2 \mathrm{~cm}$ below the costal margin, but his spleen was nonpalpable. Laboratory test results showed a leukocytosis, as well as high levels of total bilirubin $(29.2 \mu \mathrm{mol} / \mathrm{L})$, conjugated bilirubin $(7.7 \mu \mathrm{mol} / \mathrm{L})$, AST $(48 \mathrm{U} / \mathrm{L})$, total cholesterol $(7.58 \mathrm{mmol} / \mathrm{L})$, triglycerides (1.82 mmol/L), LDL-C (5.29 mmol/L), and VLDL-C $(0.83 \mathrm{mmol} / \mathrm{L})$, but his HDL-C level was normal $(0.67 \mathrm{mmol} / \mathrm{L})$.

Abdominal ultrasonography showed hepatosplenomegaly with moderate diffuse parenchymal changes in the liver (liver steatosis) and pancreas. Arteriosclerotic vascular disease with hemodynamically relevant stenotic brachiocephalic vessels $(20 \%-35 \%)$ was found on brachiocephalic vessel ultrasonography. Upper gastrointestinal endoscopy revealed regions of flat yellow- and brown-speckled pigmented mucosa from the descending part of the duodenum to the fourth part ( $\triangleright$ Video 1 ). Histopathological examination of a biopsy taken from the duodenal mucosa showed numerous macrophages containing brownish granules in their cytoplasm ( $>$ Fig. 1). Staining of the specimen with Perls' stain for iron-containing deposits was completely negative ( $\mathbf{F i g . 2}$ ). An ultrasonography-guided liver biopsy was performed, the results of which revealed moderate histologic hepatitic activity, fibrous degeneration (grade 3), and severe steatosis with an accumulation of foam cells. Homozygosity for pSer103Arg+/0 IVS81G>A was found on genetic sequence analysis of the LIPA gene. Lysosomal acid lipase (LAL) defi-
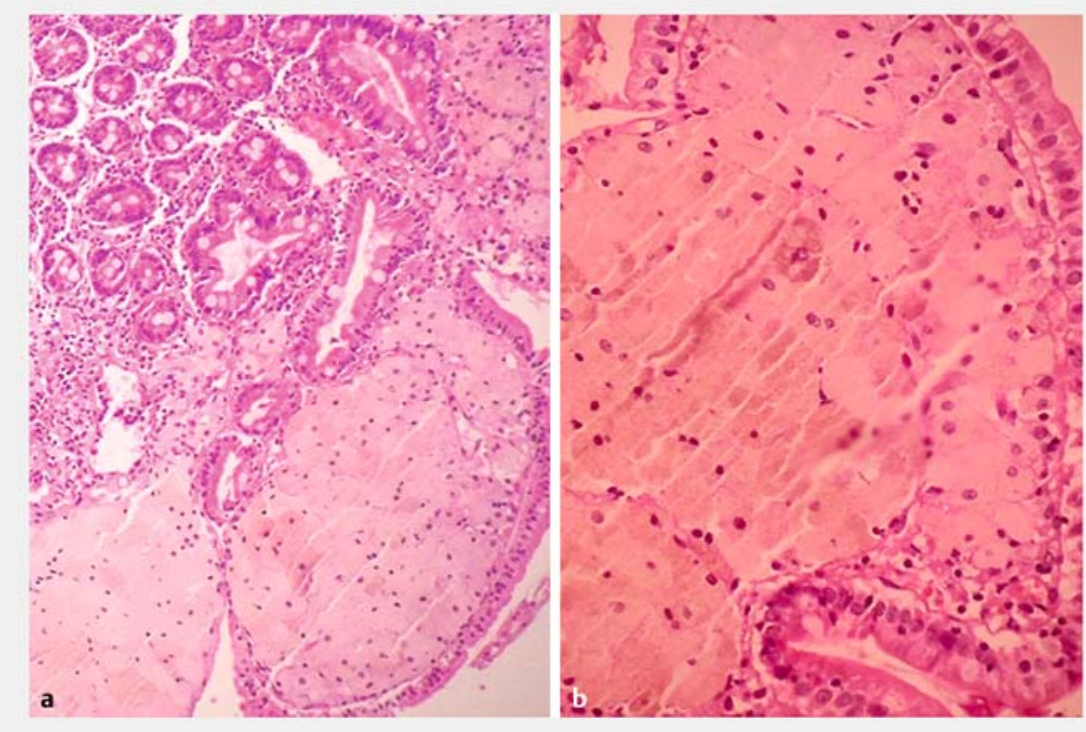

- Fig. 1 Histopathological images from a biopsy of the duodenal mucosa stained by hematoxylin and eosin (H\&E) showing numerous macrophages containing brownish granules in their cytoplasm, magnification: $\mathbf{a} \times 100$; $\mathbf{b} \times 400$.

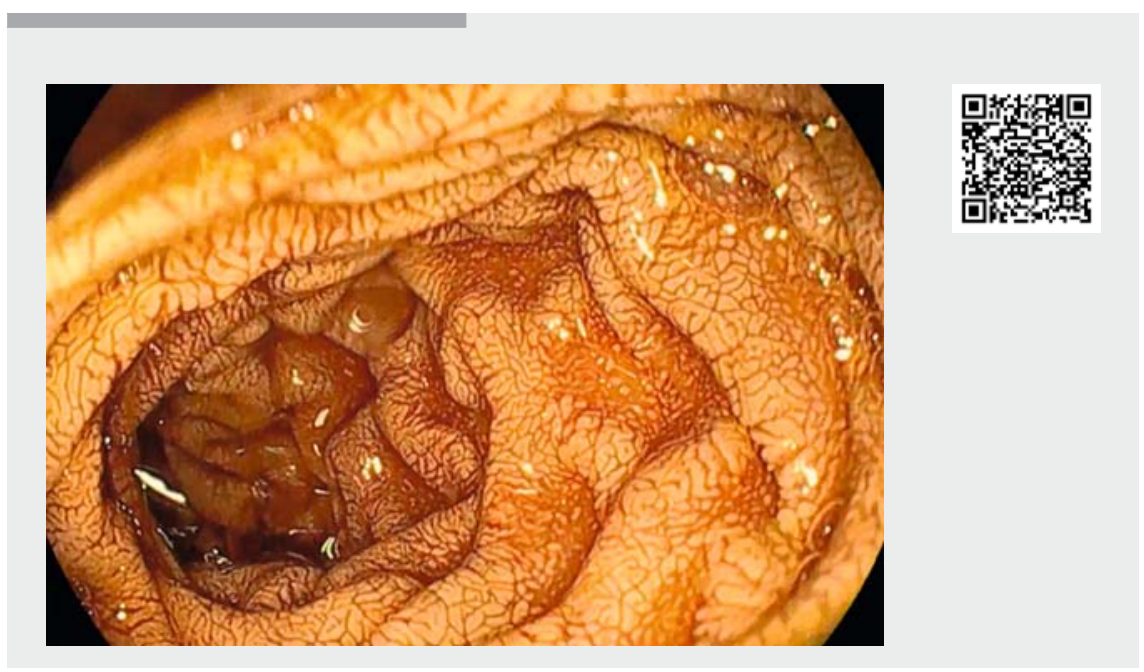

Video 1 Upper gastrointestinal endoscopy showing regions of flat yellow- and brownish-speckled pigmented mucosa in the duodenum. The biopsy showed duodenal pseudomelanosis.

ciency cholesteryl ester storage disease (CESD) was confirmed.

LAL deficiency is a rare (orphan) autosomal recessive lysosomal lipid storage disorder caused by mutations in the $\mathrm{LAL}$ gene (LIPA), which is characterized by the accumulation of cholesteryl esters and triglycerides [1,2]. Depending on the residual enzyme activity, two different presentations may be seen: an early- 


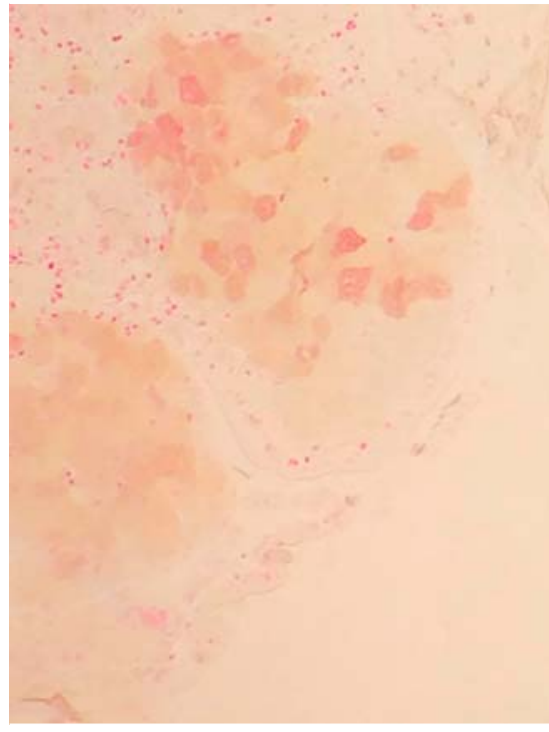

- Fig. 2 Histopathological image of the biopsy with Perls' staining showing that the pigment was negative for iron-containing deposits.

onset severe and lethal phenotype known as Wolman disease - absent or $<1 \%$ of normal LAL activity - or a late-onset attenuated phenotype known as CESD $1 \%-12 \%$ of normal LAL activity $[1,2]$. Over 40 LIPA mutations on chromosome $10 q 23.2-23.3$ that cause CESD and Wolman disease have been identified [2,3]. There have been 135 CESD patients described in the literature [4].

Endoscopy_UCTN_Code_CCL_1AB_2AZ_3AZ

\section{Competing interests}

None

The authors

Pavel V. Pavlov' ${ }^{1}$, Andrey P. Kiryukhin' ${ }^{\text {, }}$ Alexander S. Tertychnyi ${ }^{2}$

1 Endoscopy Unit, The Second University Clinic, I.M. Sechenov First Moscow State Medical University, Sechenov University, Moscow, Russia

2 Department of Pathology, I.M. Sechenov First Moscow State Medical University, Sechenov University, Moscow, Russia

\section{Corresponding author}

\section{Andrey P. Kiryukhin, MD, PhD}

Endoscopy Unit, The Second University Clinic, I.M. Sechenov First Moscow State Medical University (Sechenov University), 1 build.1. Pogodinskaya St., Moscow, 119435, Russia

a.p.kiryukhin@gmail.com

\section{References}

[1] Pant M, Oshima K. Cholesteryl ester storage disease: An underdiagnosed cause of cirrhosis in adults. Ann Diagn Pathol 2017; 31: $66-70$

[2] Strebinger G, Müller E, Feldman A et al. Lysosomal acid lipase deficiency - early diagnosis is the key. Hepat Med 2019; 11: 79-88
[3] Stenson PD, Mort M, Ball EV et al. The Human Gene Mutation Database: 2008 update. Genome Med 2009; 1: 13

[4] Bernstein DL, Hülkova H, Bialer MG et al. Cholesteryl ester storage disease: review of the findings in 135 reported patients with an underdiagnosed disease. J Hepatol 2013; 58 : $1230-1243$

\section{Bibliography}

DOI https://doi.org/10.1055/a-1011-3922

Published online: 11.10.2019

Endoscopy 2020; 52: E108-E109

(c) Georg Thieme Verlag KG

Stuttgart · New York

ISSN 0013-726X

\section{ENDOSCOPY E-VIDEOS}

https:|/eref.thieme.de/e-videos

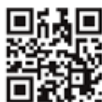

Endoscopy E-Videos is a free access online section, reporting on interesting cases and new

techniques in gastroenterological endoscopy. All papers include a high quality video and all contributions are freely accessible online.

This section has its own submission website at https://mc.manuscriptcentral.com/e-videos 